\title{
Risk of hypoglycemia during hemodialysis in diabetic patients is related to lower pre-dialysis glycemia
}

Jayme Eduardo Burmeister', Diego da Rosa Miltersteiner', Bruna Ortega Burmeister', Juliana Fernandes Campos'

\begin{abstract}
Objective: To compare the occurrence of hypoglycemia during hemodialysis in chronic kidney disease diabetic patients who present different levels of pre-dialysis glycemia both when using dialysis solutions with and without glucose. Subjects and methods: Twenty type 2 diabetic patients in maintenance hemodialysis were submitted to three dialysis sessions (at a 7-day interval each) with dialysis solutions without glucose, with glucose at $55 \mathrm{mg} / \mathrm{dL}$, and at $90 \mathrm{mg} / \mathrm{dL}$ subsequently. Blood glucose levels were measured immediately pre-dialysis and at 4 moments during the session, and values under $70 \mathrm{mg} / \mathrm{dL}$ were considered as hypoglycemia. Results: Average pre-dialysis glycemia was lower in those who presented intra-dialytic hypoglycemia than in those who did not, both in glucose-free $(140.4 \pm 50.7 \mathrm{vs} .277 .7 \pm 91.0 \mathrm{mg} / \mathrm{dL} ; \mathrm{p}=0.005 ; 95 \% \mathrm{Cl}: 46.4$ to 228.1$)$ and in glucose $55 \mathrm{mg} / \mathrm{dL}(89.5 \pm 10.6$ vs. $229.7 \pm 105.0 \mathrm{mg} / \mathrm{dL} ; \mathrm{p}<0.05 ; 95 \% \mathrm{Cl}$ : 9.8 to 270.5$)$. In patients with pre-dialysis glycemia under $140 \mathrm{mg} / \mathrm{dL}$, average intradialytic glycemia was significantly lower than pre-dialysis glycemia only when using glucose-free dialysate $(\mathrm{p}<0.0001 ; 95 \% \mathrm{Cl}: 29.9$ to 56.0 t-test). Hypoglycemia during dialysis was observed only when using glucose-free or glucose-poor dialysis solutions. Conclusions: The use of glucose-free or glucose-poor dialysis solution presents a high risk of intradialytic hypoglycemia in diabetic renal patients, especially in those with presumed better glycemic control. Arch Endocrinol Metab. 2015;59(2):137-40
\end{abstract}

Keywords

Diabetes mellitus; hypoglycemia; renal dialysis
1 Universidade Luterana do Brasil, Curso de Medicina, Canoas, RS, Brazil

Correspondence to

Jayme Eduardo Burmeister

Av. Lucas de Oliveira, 1270, ap. 301

90440-010 - Porto Alegre, RS, Brazil

jb.nefro@gmail.com

Received on Apr/25/2014 Accepted on Jan/19/2015

DOI: 10.1590/2359-3997000000026

\section{INTRODUCTION}

A symptomatic hypoglycemia (HG) during hemodialysis (HD) has been reported in chronic kidney disease $(\mathrm{CKD})$ patients since more than a decade ago (1), and it is common in diabetic (DM) individuals when dialysis is performed with a glucose-free dialysis solution $(2,3)$. Moreover, the use of glucose-added dialysate showed a significant reduction and even the absence of intradialytic HG (3), and nowadays its use is indicated and largely diffused (4). Recently, we published a study in which we compared the occurrence of HG during dialysis with different levels of glucose (5). Now we revised these data in order to verify the hypothesis that intradialytic HG episodes in DM patients could be related to pre-dialysis serum glucose levels.

\section{SUBJECTS AND METHODS}

This study was approved by the Ethics Committees in Research of Universidade Luterana do Brasil
(ULBRA), and all participants signed an informed consent form.

Twenty CKD patients in stable maintenance HD were randomly selected among all 34 adult type 2 diabetic (T2DM) individuals from an HD unit. They should be free from any hospitalization or infectious event in the past 4 weeks, and BMI should be over 20 $\mathrm{kg} / \mathrm{m}^{2}$. The patients were submitted to three mid-week HD sessions with a 7-day interval, using different glucose concentrations in the dialysate fluid - first with a glucose-free (GluZERO), later with glucose $55 \mathrm{mg} / \mathrm{dL}$ (Glu55), and then with $90 \mathrm{mg} / \mathrm{dL}$ (Glu90). In each phase, plasma glucose levels were measured immediately pre-dialysis (pre-HD glycemia), and in four standardized moments during the session (intra-HD glyce$\mathrm{mia}$ ) - at 30, 60, 150, and $240 \mathrm{~min}$. Hypoglycemia was considered as a blood glucose level under $70 \mathrm{mg} / \mathrm{dL}$ even without symptoms, as stated in previous studies $(2,3)$. Other details of the study were decribed in the original article (5). 
For the present analysis, we compared pre-HD with intra-HD average glycemia in each phase, both in those patients who presented HG episodes as in those without HG. We also studied specifically those patients with pre-HD glycemia under $140 \mathrm{mg} / \mathrm{dL}$ in each phase, comparing pre-HD to intra-HD average glycemia in each phase.

Bivariate statistical analysis was performed using GraphPad InStat 3.05 (GraphPad Software, San Diego, California, USA). Student's $t$-test was used to compare continuous variables. Statistical significance was set at $P<0.05$.

\section{RESULTS}

The 20 patients' age was $56.3 \pm 11.8$ yrs-old (mean \pm $\mathrm{SD})$. Twelve $(60 \%)$ were male. All of them were on dialysis for an average of 56.3 months and presented the diagnosis of diabetes for more than 7 years.

Five patients in GluZERO and three patients in Glu55 presented seven and five HG episodes respectively, none during Glu90.

For all individuals, mean intradialytic glycemia was significantly lower than pre-HD glycemia in each of the 3 phases, a finding more pronounced in GluZERO $(151.9 \pm 70.2$ vs. $243.4 \pm 101.8 \mathrm{mg} / \mathrm{dL})$.

Average pre-HD glycemia was lower in those who presented intra-HD episodes of $\mathrm{HG}$ than in those who did not, both in GluZERO (140.4 \pm 50.7 vs. $277.7 \pm$
$91.0 \mathrm{mg} / \mathrm{dL} ; \mathrm{p}=0.005)$ and in Glu55 (89.5 \pm 10.6 ps. $229.7 \pm 105.0 \mathrm{mg} / \mathrm{dL} ; \mathrm{p}<0.05)$ (Table 1$)$.

Among those with pre-HD glycemia under 140 $\mathrm{mg} / \mathrm{dL}$ (respectively five, six, and five patients in GluZERO, Glu55, and Glu90), mean intra-HD glycemia was significantly lower only in phase GluZERO ( $\mathrm{p}=$ 0.0015 ; $t$ test) (Table 2 ).

\section{DISCUSSION}

It is well established, especially in DM individuals, that asymptomatic hypoglycemia is usual during hemodialysis with glucose-free dialysis solution, and that a glucose-added dialysate prevents these events $(2,3,5-7)$. However, to the best of our knowledge, no one has previously studied the relationship of these hypoglycemic events with pre-HD blood glucose levels.

We observed that the occurrence of HG during the dialysis session is related to blood glucose level significantly lower, though normal, at the begining of dialysis (Table 1). Moreover, when considering only those patients with pre-HD blood glucose level under $140 \mathrm{mg} / \mathrm{dL}$, who are supposedly more prone to HG during dialysis, we found intra-HD glycemia significantly lower than pre-HD glycemia only during glucose-free dialysis (Table 2). These data seem to indicate a higher risk of intradialytic HG for DM individuals who presumably present the best glycemic control, especially when in glucose-free dialysis. Further, we found a significant

Table 1. Glycemia (pre-HD and intra-HD - mean $\pm \mathrm{SD} ; \mathrm{mg} / \mathrm{dL}$ ) in those with and without $\mathrm{HG}$ during each phase

\begin{tabular}{|c|c|c|c|c|c|c|c|}
\hline Phase & & GluZERO & & & Glu55 & & Glu90 \\
\hline Patients & All $(n=20)$ & With $H G(n=5)$ & No $H G(n=15)$ & All $(n=20)$ & With $H G(n=3)$ & No $H G(n=17)$ & All $(n=20)$ \\
\hline Pre-HD glycemia & $243.4 \pm 101.8$ & $140.4 \pm 50.7^{\star}$ & $277.7 \pm 91.0^{*}$ & $215.7 \pm 108.3$ & $89.5 \pm 10.6^{\star *}$ & $229.7 \pm 105.0^{* *}$ & $207.8 \pm 113.7$ \\
\hline Intra-HD glycemia & $151.9 \pm 70.2$ & $78.0 \pm 16.2$ & $176.4 \pm 63.8$ & $165.2 \pm 72.2$ & $77.0 \pm 41.9$ & $175.0 \pm 68.2$ & $157.6 \pm 75.4$ \\
\hline$P$ & $\begin{array}{c}<0.001 \\
95 \% \mathrm{Cl}: \\
56.2 \text { to } 125.9\end{array}$ & $\begin{array}{c}<0.0001 \\
95 \% \mathrm{Cl}: \\
35.7 \text { to } 89.0\end{array}$ & $\begin{array}{c}<0.0001 \\
95 \% \mathrm{Cl}: \\
61.1 \text { to } 141.4\end{array}$ & $\begin{array}{c}<0.02 \\
95 \% \mathrm{Cl}: \\
10.3 \text { to } 90.2\end{array}$ & $\begin{array}{c}0.62 \\
95 \% \mathrm{Cl}: \\
-41.5 \text { to } 66.5\end{array}$ & $\begin{array}{c}<0.02 \\
95 \% \mathrm{Cl}: \\
13.3 \text { to } 96.0\end{array}$ & $\begin{array}{c}<0.02 \\
95 \% \mathrm{Cl}: \\
8.4 \text { to } 91.9\end{array}$ \\
\hline
\end{tabular}

${ }^{\star} p=0.005$ (95\% Cl: 46.4-228.1) / ** $p<0.05$ (95\%Cl: 9.8-270.5); (t-test).

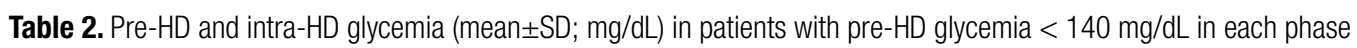

\begin{tabular}{|c|c|c|c|}
\hline & GluZERO & Glu55 & Glu90 \\
\hline Patients (n) & 5 & 6 & 5 \\
\hline Pre-HD glycemia (n) & $122.4 \pm 14.1(5)$ & $107.0 \pm 18.3(6)$ & $114.4 \pm 16.1(5)$ \\
\hline Intra-HD glycemia (n) & $79.4 \pm 12.3(20)$ & $103.7 \pm 44.2(24)$ & $127.2 \pm 49.4(20)$ \\
\hline \multirow[t]{2}{*}{$p^{*}$} & $<0.0001$ & 0.86 & 0.57 \\
\hline & $95 \% \mathrm{Cl}: 29.9$ to 56.0 & $95 \% \mathrm{Cl}:-34.8$ to 41.4 & $95 \% \mathrm{Cl}:-59.7$ to 34.1 \\
\hline
\end{tabular}


decrement of blood glucose levels during dialysis ( $\mathrm{Ta}-$ ble 1), which could be due, at least in part, to a loss of glucose in the dialysate (1-3).

All the above highlight the risk of using dialysis solution without glucose in DM patients.

As the maintenance of good glycemic control in DM patients on dialysis is related to lower mortality and better quality of life (8-13), it seems fundamental that this control must be in line with a dialysis procedure that precludes $\mathrm{HG}$.

In the early days of dialytic therapy, glucose was present in hemodialysis fluid. Later, this was followed by the wide use of glucose-free solutions in order to avoid the risk of bacterial contamination and for cost reduction $(4,14)$. This practice became usual despite reports, since that time, about possible deleterious effects related to the lack of glucose in the dialysis solution (15-17). However, this matter was recently resumed, and the presence of glucose in dialysate became widely advisable to prevent frequent symptom-free HG and its consequences in DM patients, as the involvement of the central nervous system $(3,4)$. The frequent repetition of these asymptomatic events leads to a cerebral adaptation to low blood glucose levels, and this has been attributed as the cause of the lack of symptoms (18). In consequence, these patients are submitted to the risk of a progressively compromised cognitive function (19-21). Ramirez and cols. (16), in 1986, first called attention to electroencephalographic abnormalities when using glucose-free hemodialysis solutions. Recently, Cui and cols. used metabonomics to compare the metabolic properties of maintenance hemodialysis patients with and without glucose in dialysate. Their results showed that glucose-added dialysate was more efficient than glucose-free fluid in providing energy to the central nervous system (22).

In our study, the small number of patients, the lack of information about some clinical data (for instance, the presence of autonomic neuropathy, and a proper method of regular glycemic control), and also some characteristics peculiar to this kind of study (e.g., the different ranges of time between daily meals and the start of the dialysis session; and the individual administration schedule of insulin or oral hypoglycemic drugs) - all may have caused some influence on our results. Nevertheless, the strength of our data relies on the fact of being obtained under usual daily clinical conditions, this way reflecting the reality of regular hemodialysis treatment in diabetics.
In conclusion, T2DM patients with lower, though normal, pre-HD glycemia seem to present higher risk of developing intradialytic $\mathrm{HG}$ when using a dialysis solution without glucose or with low concentration of glucose. These findings allow to suppose that diabetic CKD patients who are in best glycemic control present higher risk of HG episodes during HD sessions with a glucose-free (or a glucose-poor) dialysis solution. In this way, while optimizing diabetes treatment and glycemic control, we would be providing a worse dialysis therapy if a glucose-free or glucose-poor dialysis solution was used. Finally, these data strengthens the importance of an adequate level of glucose in the composition of hemodialysis solution.

Disclosure: no potential conflict of interest relevant to this article was reported.

\section{REFERENCES}

1. Jackson MA, Holland MR, Nicholas J, Talbot M, Spencer H, Lodwick $R$, et al. Occult hypoglycemia caused by hemodialysis. Clin Nephrol. 1999;51:242-7.

2. Jackson MA, Holland MR, Nicholas J, Lodwick R, Foster D, Macdonald IA. Hemodialysis-induced hypoglycemia in diabetic patients. Clin Nephrol. 2000;54:30-4.

3. Burmeister JE, Scapini A, da Rosa Miltersteiner D, da Costa MG, Campos BM. Glucose-added dialysis fluid prevents asymptomatic hypoglycaemia in regular haemodialysis. Nephrol DialTransplant. 2007;22:1184-9.

4. Hoenich N,Thijssen S, KitzlerT, Levin R, Ronco C. Impact of water quality and dialysis fluid composition on dialysis practice. Blood Purif. 2008;26:6-11.

5. Burmeister JE, Campos JF, Miltersteiner DR. Effect of different levels of glucose in the dialysate on the risk of hypoglycaemia during hemodialysis in diabetic patients. J Bras Nefrol. 2012;34:323-7.

6. Simic-Ogrizovic S, Backus G, Mayer A, Vienken J, Djukanovic L, Kleophas W. The influence of different glucose concentrations in haemodialysis solutions on metabolism and blood pressure stability in diabetic patients. In J Artif Organs. 2001;24:863-9.

7. Sangill M, Pedersen EB. The effect of glucose added to the dialysis fluid on blood pressure, blood glucose, and quality of life in hemodialysis patients: a placebo-controlled crossover study. Am J Kidney Dis. 2006;47:636-43.

8. Ricks J, Molnar MZ, Kovesdy CP, Shah A, Nissenson AR, Williams $M$, et al. Glycemic control and cardiovascular mortality in hemodialysis patients with diabetes - a 6-year cohort study. Diabetes. 2012;61:708-15.

9. Adler A, Casula A, Steenkamp R, Fogarty D, Wilkie M, Tomlinson $L$, et al. Association between glycemia and mortality in diabetic individuals on renal replacement therapy in the United Kingdom. Diabetes Care. 2014;37(5):1304-11.

10. Oomichi T, Emoro M, Tabata T, Morioka T, Tsujimoto $Y$, Tahara $H$, et al. Impact of glycemic control on survival of diabetic patients on chronic regular hemodialysis: a 7-year observational study. Diabetes Care. 2006;29:1496-500.

11. McMurray SD, Johnson G, Davis S, McDougall K. Diabetes education and care management significantly improve patient outcomes in the dialysis unit. Am J Kidney Dis. 2002;40:566-75. 
12. Tzamaloukas AH, Murata GH, Zager PG, Eisenberg B, Avasthi PS. The relationship between glycemic control and morbidity and mortality for diabetic on dialysis. ASAIO J. 1993;39:880-5.

13. Ramirez S, McCullough KP,Thumma JR, Nelson RG, Morgenstern $H$, Gillespie BW, et al. Hemoglobin A1c levels and mortality in the diabetic hemodialysis population - Findings from the Dialysis Outcomes and Practice Patterns Study (DOPPS). Diabetes Care. 2012;35:2527-32.

14. Parsaw F, StewartW.The composition of dialysis fluid. In: DruckerWM, Parsons FM, Maher JF, eds. Replacement of Renal Function by Dialysis -ATextbook of Dialysis. Martinus Nijhoff, Boston, MA: 1983; p. 148-70.

15. Gutierrez A, Bergstrom J, Alvestrand A. Hemodialysis-associated protein catabolism with and without glucose in the dialysis fluid. Kidney Int. 1994;46:814-22.

16. Ramirez G, Bercaw BL, Butcher DE, Mathis HL, Brueggemeyer $C$, Newton JL. The role of glucose in hemodialysis: the effects of glucose-free dialysate. Am J Kidney Dis. 1986;7:413-20.

17. Wathen RL, Keshaviah P, Hommeyer P, Cadwell K, Comty CM. The metabolic effects of hemodialysis with and without glucose in the dialysate. Am J Clin Nutr. 1978;31:1870-5.
18. Amiel S. Reversal of unawareness of hypoglycaemia. N Engl J Med. 1993;329:876-7.

19. DeFeo P, Gallai V, Mazzota G, Crispino G, Torlone E, Perriello G, et al. Modest decrements in plasma glucose concentrations cause early impairment in cognitive function and later activation of glucose counterregulation in the abscence of hypoglycemic symptoms in normal man. J Clin Invest. 1988;82:436-44.

20. Heller SR, MacDonald IA. The measurement of cognitive function during acute hypoglycemia: experimental limitations and their effect on the study of hypoglycemia unawareness. Diabet Med. 1996;13:607-15.

21. Maran A, Lomas J, MacDonald IA, Amiel SA. Lack of preservation of higher brain function during hypoglycemia in patients with intensively treated IDDM. Diabetologia. 1995;38:1412-8.

22. Cui L, MengY, Xu D, Feng YY, Chen GY, Hu B, et al. Analysis of the metabolic properties of maintenance hemodialysis patients with glucose-added dialysis based on high performance liquid chromatography quadrupole time-of-flight mass spectometry. Ther Clin Risk Manag. 2013;9:417-25. 